\title{
Influence of workplace incivility on the quality of nursing care
}

\author{
Abdualrahman Saeed Alshehry PhD, RN, Asst. Professor ${ }^{1}$ (D) | Nahed Alquwez PhD, RN, \\ Asst. Professor $^{2}$ | Joseph Almazan DNS, RN, Asst. Professor ${ }^{3}$ (D) | Ibrahim \\ Mohammed Namis BSN, MSN, RN, Nursing Supervisor ${ }^{4}$ | Jonas Preposi Cruz PhD, MAN, RN, \\ Lecturer $^{2}$
}

${ }^{1}$ Medical-Surgical Department, College of Nursing, King Saud University, Riyadh, Saudi Arabia

${ }^{2}$ Nursing Department, College of Applied Medical Sciences, Shaqra University, Al Dawadmi, Saudi Arabia

${ }^{3}$ Department of Nursing

Education, Nazarbayev University, NurSultan, Kazakhstan

${ }^{4}$ Nephrology and Hemodialysis Department, King Fahd Central Hospital, Jizan, Saudi Arabia

\section{Correspondence}

Jonas Preposi Cruz, Nursing Department, College of Applied Medical Sciences, Shaqra University, PO Box 1678, Al Dawadmi 11911, Saudi Arabia.

Email: cruzjpc@su.edu.sa; cruzjprn@gmail. com

Funding information

This study received funding from the Deanship of Scientific Research, College of Nursing Research Centre at King Saud University, Saudi Arabia.

\begin{abstract}
Aims and objectives: To examine the influence of workplace incivility on the quality of nursing care.

Background: Recent evidence describes workplace incivility as a serious concern in the healthcare setting worldwide. Exposure to workplace incivility can alter a nurse's behaviour, thought process and perspective towards the nursing profession. However, there is insufficient evidence to determine whether workplace incivility might be associated with the quality of nursing care in Saudi Arabia.
\end{abstract}

Design: A quantitative and cross-sectional study.

Method: A survey was carried out amongst 378 nurses in two government hospitals in Saudi Arabia from February 2018-May 2018 using the Nurse Incivility and quality of nursing care scales. Multivariate multiple regression was performed to investigate the influence of the uncivil experiences of nurses from different sources on the different aspects of quality of nursing care. The study adhered to STROBE guideline (see Appendix S1).

Results: The overall mean of the quality of nursing care scale was $3.14(S D=0.66$ ) from a scale of $1-5$, with patient satisfaction receiving the highest mean dimension (mean $=3.27, S D=0.72$ ) and health promotion the lowest mean dimension (mean $=3.08, S D=0.74$ ). Experience in the present hospital and the hospital were associated with the overall quality of nursing care. General and nurse incivility exerted a multivariate effect on overall quality of nursing care and its different dimensions.

Conclusion: General incivility and nurse incivility were found to negatively impact quality of nursing care and its different dimensions.

Relevance to clinical practice: Stronger policies geared towards eliminating workplace incivility should be implemented as uncivil acts can lead to poor quality of nursing care. Nurse administrators and nurses should be pro-active in recognising, preventing, approaching, reporting and intervening with uncivil acts in the hospital to protect these workers from these types of behaviours and avoid their negative impacts on patient care.

\section{KEYWORDS}

incivility, nurses, nursing care, quality of nursing care, Saudi Arabia 


\section{1 | INTRODUCTION}

Workplace incivility (WPI) is a complex issue that has gained significant attention in recent decades. Recent evidence describes WPI as a serious concern in the healthcare setting worldwide (Spiri, Brantley, \& McGuire, 2016). Although nursing is a profession that is committed to serving people, it has greatly changed its nature due to the rapid-paced environment in which nurses work and incivility is often disregarded or ignored (Ibrahim \& Qalawa, 2016). Exposure to WPI can alter a nurse's behaviour, thought process and perspective towards the nursing profession (Abdollahzadeh, Asghari, Ebrahimi, Rahmani, \& Vahidi, 2017). Hence, WPI is highly likely to affect a nurse's overall health or well-being, work performance and quality of patient care.

The Joint Commission (JC, 2008) calls for eradication of WPI behaviours that challenge patient safety. To maintain an incivility-free workplace, the nursing management must nurture a healthy work environment (JC, 2008). Existing investigations acknowledge the nursing management's role in reducing incivility by delivering quality staff nurses' education and dealing with behavioural issues (Abolfazl Vagharseyyedin, 2015; Heydari, Rad, \& Rad, 2015). Thus, outcomes pertaining to the prevalence of unacceptable behaviours have dropped significantly (Abolfazl Vagharseyyedin, 2015); overall, however, this pervasive problem cannot be totally eliminated in the clinical workplace. For example, Abdollahzadeh et al. (2017) reported that some nurses recognise this workplace behavioural concern to be normally present in their workplace, which cannot be removed easily. Hence, most behavioural issues are unreported. The main challenge encountered by many nurses from the workplace perspective is one-sided, and its full complexity has not been recognised. A better understanding of WPI in clinical practice could promote intervention, thereby improving nurses' productivity, work satisfaction and fulfilment whilst eliminating patient errors (Spiri et al., 2016). To clarify the implications for the workplace that stem from uncivil behaviours and unhealthy work environments, the issue of incivility must be addressed. This study gives a chance for nurses to share their perspective on WPI and reflect on the influence of their experiences that may affect the quality of care given to patients.

\section{1 | Background of the study}

Workplace incivility is a significant issue in clinical practice. Workplace incivility is troubling not only to the healthcare provider but also to the delivery of care beneath the shade of incivility (Abdollahzadeh et al., 2017). Pearson, Andersson, and Wegner (2001) stated that "WPI is low-intensity divergent behaviour with uncertain intention to injure a person, violating the workplace standards and norms for reciprocal respect." In a study, Holm, Torkelson, and Backstrom (2015) reflected that if incivility cannot be resolved, it may advance to more threatening circumstances or actions. A person who experiences WPI may bear various harmful behaviours and negative psychological effects, such as anxiety, exhaustion, anger stress, sleeplessness and depression (Holm et al., 2015).

\section{What does this paper contribute to the wider global clinical community?}

- The study identifies areas of nursing care that should be enhanced by nurses, such as health promotion and functional readaptation to ensure the highest quality of nursing care rendered to patients.

- The study provides evidence on the negative influence of nurses' experiences of workplace incivility on the quality of nursing care they provide to patients.

- The study provides implications to nurse administrators and nurses to be pro-active in recognising, preventing, approaching, reporting and intervening with uncivil acts in the hospital to protect these workers from these types of behaviours and avoid their negative impacts on patient care.

Nurses, like any other healthcare professional, have the primary responsibility of providing holistic care (e.g., physical, mental, social, spiritual and emotional), including anticipating patient needs, ensuring patient safety, implementing effective nursing interventions and ensuring the continuity of patient care (American Nurses Association [ANA], 2019). The health promotion and disease prevention practice of nurses could result in positive health outcomes, including medication adherence, patients' self-management and improved patient health condition and quality of life (Kemppainen, Tossavainen, \& Turunen, 2012). Coupled with the nurses' work environment, patient-nurse interactions could be easily taken advantage of and used to conduct health teachings and provide necessary care. However, if the workplace environment of nurses is troubling to them and violates their workplace standards, their delivery of care may be affected (Zhou, Yan, Che, $\&$ Meier, 2015). Thus, the workplace environment could be challenging to nurses as providers of care because of negative workplace experiences. Abdollahzadeh et al. (2017) and Heydari et al. (2015) noted that nurses encounter numerous WPI incidents (e.g., administration bullying, nurses bullying patients, patients bullying nurses and nurses bullying nurses). Workplace incivility may pose significant negative consequences for nurses, patients and nursing administration. Other empirical works reveal that WPI can cause job burnout, diminish nursing teamwork, increase absenteeism, promote poor work performance, cause medication administration errors and decrease the quality of patient care (Jaradat et al., 2016; Shi et al., 2018; Zhou et al., 2015).

Workplace incivility has been documented internationally as significantly prevalent in the workplaces of nurses. For example, in one study in Iran, high incivility prevalence was reported amongst 34 Iranian nurses from seven hospitals (Abdollahzadeh et al., 2017). In one study in China, WPI increased anxiety and burnout level, as reported by 696 new nurses (Shi et al., 2018). According to Spiri et al. (2016), uncivilised work environments are linked to 
decreased performance quality in the workplace, as reported by 155 US nurses. These incidents not only exert a serious effect on nurses' well-being but also derail their ability to provide patient care. In Saudi Arabia, WPI was discovered to be a concern amongst nurses (Alshehry et al., 2019). Furthermore, nurses who experience bullying and WPI have a great intent to resign. Most nurses work in different countries with different cultures (Almutairi, 2015). Some expatriate nurses may feel incompetent in understanding the sensitivity of the Saudi culture (Almutairi, 2015). Consequently, they may feel unrespected, reprimanded, harassed, emotionally abused and mobbed by their supervisor. A recent study by Alshehry et al. (2019) revealed 165 (29\%) Saudi nurses and 268 (71\%) expatriate nurses working in two Saudi hospitals who reported experiencing WPI, most of which came from patients/visitors.

Unacceptable behaviours can pose a risk to patient safety and quality care. According to Freitas, Silva, Minamisava, Bezerra, and Sousa (2014), QNC is based on patients' personal views as receivers of healthcare services. In order to provide QNC, nurses should be knowledgeable and skilful in patient care (Kieft, de Brouwer, Francke, \& Delnoij, 2014). Patients necessitate from nurses to embrace certain characters (e.g., empathy, kindness and caring) as some indicators of quality nursing care (Al-Hussami, Al-Momani, Hammad, Maharmeh, \& Darawad, 2017). However, measuring the QNC is not only about nurses' performance but also about how nursing is organised and delivered within healthcare institutions (Freitas et al., 2014). In the study of Alshehry et al. (2019), good workplace environment of nurses improves the patient-centred care delivery. In addition, patients are also satisfied with the care delivered if there is an interdisciplinary collaboration between nurses and other healthcare professionals (Al-Hussami et al., 2017). Hospital-related services such as clean bed linen, available bathroom and well-ventilated room also affect the QNC (Al-Hussami et al., 2017). It is likely that the more available the services and well clean the hospital environment, the higher the QNC. Therefore, quality is the result of both conforming to a common standard that can be objectively measured, incorporate considerations of equity, accessibility, acceptability, efficiency and effectiveness of services rendered. Nevertheless, despite the positive effect of good workplace condition to the QNC, nurses were constantly challenged to take responsibility and accountability for the quality of their practice.

Extensive research has elucidated the need for nurses to be free from all types of workplace conflict and create a nurturing and safe respectful work environment to promote positive work outcomes (Loi, Loh, \& Hine, 2015; Oyeleye, Hanson, O'Connor, \& Dunn, 2013). Although WPI and its influencing factors have been studied by several researchers (Loi et al., 2015; Oyeleye et al., 2013), the results are often based on other countries and cannot be generalised, especially in a country with diverse cultures. Although the literature discusses how WPI interventions can improve civility (Holm et al., 2015), their effects are not persistent over the long term. Quantitative analyses of the influence of WPI on the quality of nursing care (QNC) provided by multicultural nurses working in Saudi Arabia have been limited. Therefore, serious discussions are needed to achieve a better understanding of the factors, outcomes and methods of WPI prevention (Jaradat et al., 2016; Shi et al., 2018). Findings may provide valuable insights into a nurse's perception of WPI prevention and management and benefit staff nurses, nurse supervisors and the management in the long run. Gaining an understanding of WPI factors in Saudi hospitals may provide new perspectives on how to protect nurses and ensure that their rights are preserved.

Based on the empirical evidence discussed above, we hypothesised that: (a) there is significant difference between hospitals on the nurses' experience of WPI, (b) demographic and work-related variables are associated with QNC, and (c) WPI is associated with perceived QNC. Therefore, this investigation examined the influence of WPI, as well as the nurses' demographic and work-related variables, on QNC in two hospitals in Saudi Arabia. It also examined the difference between hospitals on the nurses' experience of WPI.

\section{2 | METHODS}

\section{1 | Design}

This descriptive, cross-sectional, comparative study is the second part of a study that examines the WPI experiences of nurses, their perceived professional quality of life and QNC in two government hospitals in Saudi Arabia. An article reporting on the impact of WPI on the professional quality of life of nurses was previously published (Alshehry et al., 2019). This current paper reported the results of an examination of the influence of WPI on QNC. The methods of the study were described by Alshehry et al. (2019). The study adhered to STROBE guideline (see Appendix S1).

\section{2 | Settings and samples}

The study was conducted in two government hospitals, one with 450 beds (Hospital A) and another with 300 beds (Hospital B), located in the southern and central regions of Saudi Arabia, respectively. Registered nurses in the country with a minimum of 6-month experience in the healthcare facility were included in the study. Nurses of any nationality and who were proficient in speaking, reading and writing in English were also included. The study was limited on staff nurses, and nurses with managerial and administrative roles were excluded. From the total number of 875 nurses from the two hospitals, 656 nurses were deemed qualified based on the inclusion criteria and were invited to participate; 594 nurses gave their consent to participate, but only 378 questionnaires were returned and included in the analyses (response rate $=63.6 \%$; Alshehry et al., 2019). The statistical power achieved by the sample size was calculated using G*Power 3.1 (Faul, Erdfelder, Buchner, \& Lang, 2009). The sample size of 378 was employed for the power analyses, and a 23-predictor variable equation was used as a baseline. The alpha was set at 0.05 , and the effect sizes used were based from Cohen (1977; small $=0.02$, medium $=0.15$ and large $=0.35$ ). The analyses revealed $95.0 \%, 95.1 \%$ and $95.1 \%$ power for detecting small, medium and large effects. Hence, the sample was more than adequate to detect small to large effect size level. 


\section{3 | Instrument}

The nurses' perception of QNC was measured by the QNC scale by Martins, Gonçalves, Ribeiro, and Tronchin (2016). This scale measures the perception of nurses regarding activities that represent QNC. The QNC scale includes 25 items, which are rated using a fourpoint Likert scale ( 1 = never, 2 = rarely, $3=$ often and $4=$ always). The scale is composed of seven categories, namely "patient satisfaction, health promotion, prevention of complication, well-being and selfcare, functional readaptation, nursing care organisation, and responsibility and rigour." The scores in each category can be attained by calculating the mean. High mean values indicate high QNC (Martins et al., 2016). The computed Cronbach alpha of the entire QNC scale was 0.94 . The computed Cronbach alpha values of the subscales for "patient satisfaction, health promotion, prevention of complications, well-being and self-care, functional readaptation, nursing care organisation and responsibility and rigour" were 0.744, 0.740, 0.779, $0.862,0.830,0.684$ and 0.855 , respectively.

To measure the nurses' WPI experiences from different sources, the NIS by Guidroz, Burnfield-Geimer, Clark, Schwetschenau, and Jex (2010) was used. This scale probes nurses' experiences of uncivil acts from doctors, other nurses, patients/visitors and supervisors. The NIS comprises thirty-seven five-point Likert scale items ( 1 = strongly disagree, 2 = disagree, 3 = neither agree nor disagree, 4 = agree and 5 = strongly agree). The NIS is a baseline assessment of incivility and is intended to gauge the sources and types of incivility that are most problematic. Item means were calculated and used to calculate the subscale means. Possible mean scores can range from 1-5. High mean values indicate that high levels of incivility are experienced from the specific sources. Higher mean values also indicate sources of incivility that is most problematic (Guidroz et al., 2010). The Cronbach alpha of the eight factors of the NIS ranged from 0.81-0.94. The scale also manifested excellent convergence and discriminant validity. Principal axis factor analysis supported the eight factors of the scale: two factors comprised general incivility, three factors made up nurse incivility, one factor made up physician incivility, one factor comprised supervisor incivility, and one factor comprised patient/visitor incivility. The total variance explained by the factors was $71.64 \%$. The NIS also showed correlations with conflict and work stress, thereby strengthening its construct validity (Guidroz et al., 2010). The computed Cronbach alpha values of the different factors of the NIS in the present sample ranged from $0.78-0.85$.

\subsection{Data collection}

The survey was carried out from February 2018-May 2018. The schedule of the nurses was obtained from the nursing office of the two hospitals and used to create data collection schedule. Two researchers approached the respondents to invite them to join the study; those who gave their consent were given questionnaires with a cover letter containing information about the study. The researchers instructed the nurses on how to respond to the survey, and the questionnaires were retrieved from the nurses the following day.
This process was continued until the end of the data collection period. Answered questionnaires were secured in a cabinet.

\subsection{Ethical considerations}

The Institutional Review Board of King Fahad Medical City (IRB No. 18-028E) reviewed and approved the protocol of the study. Information regarding the study, including the aims of the investigation and its significance, the participation of the nurses, the right to refuse participation and the right to terminate participation, was thoroughly discussed with each respondent before asking them to participate and sign an informed consent. Respondent and data confidentiality was protected by asking the nurses not to write their names in the questionnaires, by reporting the results without mentioning the identities of the respondents and by keeping the questionnaires in a secured cabinet. No incentive was offered for the participation of the respondents.

\section{6 | Data analysis}

Data were entered into SPSS version 22.0 for data analyses. The mean and standard deviation were computed for the items and subscales of the WPI and QNC variable. The means of the subscales were ranked to identify which dimension was the lowest and highest in both WPI and QNC. Inferential statistics, such as independent-samples $t$ test, oneway analysis of variance and Pearson's product-moment correlation, were calculated to identify the relationships and differences between the QNC variable and the respondents' demographic and work-related variables. The Tukey HSD test was performed when ANOVA revealed significant findings. To investigate the effect of the different sources of WPI (predictor variables) on the subscales of QNC (dependent variables), multivariate multiple regression analysis was conducted. Multiple linear regression analyses were performed to determine the individual impact of the predictor variables on the dependent variables. A $p$ value less than .05 was considered statistically significant. The $95 \%$ confidence intervals were also reported as necessary.

\section{3 | RESULTS}

\section{1 | Demographic and work-related characteristics of the respondents}

Amongst the 378 nurse respondents in this study, 252 (66.7\%) were employed in Hospital A and 126 (33.3\%) were employed in Hospital B. Most of the respondents were females ( $n=326,86.2 \%$ ), and only $52(13.8 \%)$ were males. The mean age was $30.00(S D=5.02)$ years. Saudi nurses comprised $29.1 \%(n=110$ ) of the sample, whilst Filipino and Indian nurses constituted $27.2 \%(n=103)$ and $43.7 \%(n=165)$ of the sample, respectively. Approximately $53.2 \%(n=201)$ of the respondents were married; the rest were single. More than half of the respondents had baccalaureate degrees in nursing ( $n=291,77.0 \%$ ), and the remaining held diplomas in nursing. The nurses' mean years of experiences were $7.05(S D=4.68$ ) years in the nursing profession, $4.78(S D=3.89)$ years in Saudi Arabia and $2.08(S D=3.43)$ years in 
the current hospital. The nurses worked in various clinical areas, including the Emergency Room (5.0\%), the Outpatient Department (6.9\%), the Medical Department (24.3\%), the Surgical Department (19.8\%), the Intensive Care Unit (16.6\%), the Operating Room (6.9\%), the Obstetric Department (7.7\%), the Artificial Kidney Unit (5.3\%) and the Paediatric Department (7.4\%) (Alshehry et al., 2019).

\section{2 | Results of descriptive analysis of workplace incivility}

The descriptive analysis results of the WPI experiences of nurses were previously reported by Alshehry et al. (2019). This variable was measured using the Nursing Incivility Scale (NIS) by Guidroz et al. (2010). As reported by Alshehry et al. (2019), the mean scores on different subscales of general incivility, nurse incivility, supervisor incivility, physician incivility and patient/visitor incivility were 2.28 ( $S D=0.66), 2.18(S D=0.69), 1.90(S D=0.66), 2.42(S D=0.79)$ and $2.44(S D=0.80)$, respectively.

\section{3 | Perceived quality of nursing care and its association with demographic and work- related variables}

The item and subscale means of the QNS scale are summarised in Table 1. The overall mean of the scale was $3.14(S D=0.66)$, and the subscale means ranged from $3.08(S D=0.74)-3.27(S D=0.72)$, thereby indicating that the nurses perceived their QNC to be moderate. Patient satisfaction was perceived to have the highest quality amongst the seven subscales, followed by nursing care organisation (mean $=3.20$, $S D=0.80$ ), prevention of complication (mean $=3.17, S D=0.72$ ), well-being and self-care (mean $=3.16, S D=0.76$ ), responsibility and rigour (mean $=3.11,0.71$ ) and functional readaptation (mean $=3.09$, $S D=0.76$ ). Health promotion was perceived to have the lowest quality.

Amongst the demographic and work-related characteristics measured, only the total length of nursing experience in the current hospital and the hospital (workplace) had significant associations with perceived QNC. As indicated in Table 2, the total length of nursing experience in the hospital had a weak but positive correlation with QNC ( $r=.12, p=.016)$. Moreover, nurses working in Hospital $\mathrm{B}$ (mean $=3.49, S D=0.19$ ) reported a higher $\mathrm{QNC}$ than nurses in Hospital A (mean $=2.97, S D=0.74, t=-10.60, p<.001)$.

\section{4 | Influence of workplace incivility on perceived quality of nursing care}

The WPI experiences of the nurses from different sources (general incivility, nurse incivility, supervisor incivility, physician incivility and patient/visitor incivility), together with the nurses' demographic and work-related characteristics, were subjected to multivariate multiple regression to test their multivariate impacts on the seven subscales and overall perceived QNC. The results of the multivariate multiple regression analysis with Wilks' lambda test, which examined the multivariate effects of predictor variables on the subscales and overall perceived QNC, are reflected in Table 3. The hospital in which the nurses worked (Wilks' lambda $=0.69, p<.001$ ), general incivility (Wilks' lambda $=0.95, p=.031$ ) and nurse incivility (Wilks' lambda $=0.96, p=.035$ ) were found to have multivariate effects on the dependent variables.

Standard multiple regression analyses were conducted to examine the individual effects of the predictor variables on the individual subscales and overall perceived QNC. The results of the individual standard multiple regression are summarised in Tables 4 and 5. As indicated, nurses working in Hospital B perceived their overall QNC to be higher than nurses in Hospital $\mathrm{A}(\beta=0.72, p<.001,95 \% \mathrm{Cl}=0.58$, $0.86)$. This relationship was consistent for all subscales: patient satisfaction ( $\beta=0.56, p<.001,95 \% \mathrm{Cl}=0.39,0.73$ ), health promotion ( $\beta=0.63, p<.001,95 \% \mathrm{Cl}=0.47,0.79$ ), prevention of complications ( $\beta=0.47, p<.001,95 \% \mathrm{Cl}=0.30,0.64)$, well-being and self-care $(\beta=0.77, p<.001,95 \% \mathrm{Cl}=0.60,0.94)$, functional readaptation ( $\beta=0.81, p<.001,95 \% \mathrm{Cl}=0.65,0.98)$, nursing care organisation $(\beta=0.68, p<.001,95 \% \mathrm{Cl}=0.49,0.87)$ and responsibility and rigour $(\beta=0.82, p<.001,95 \% \mathrm{Cl}=0.58,0.86)$.

Moreover, a unit increase in the general incivility scores of the nurses corresponded to 0.14 ( $p=.039,95 \% \mathrm{Cl}=-0.28,-0.01$ ), 0.23 $(p=.001,95 \% \mathrm{Cl}=-0.36,-0.10), 0.14(p=.046,95 \% \mathrm{Cl}=-0.28$, $-0.00), 0.19(p=.006,95 \% \mathrm{Cl}=-0.33,-0.06), 17(p=.015,95 \%$ $\mathrm{Cl}=-0.30,-0.03), 0.18(p=.023,95 \% \mathrm{Cl}=-0.33,-0.03), 18$ $(p=.004,95 \% \mathrm{Cl}=0.004,95 \% \mathrm{Cl}=-0.30,-0.06)$ and $0.18(p=.002$, $95 \% \mathrm{Cl}=-0.29,-0.06)$ unit decreases in scores of patient satisfaction, health promotion, prevention of complications, well-being and self-care, functional readaptation, nursing care organisation, responsibility and rigour and overall QNC, respectively. Similarly, an increase of one unit in nurse incivility scores resulted in a decrease in the scores in prevention of complications $(\beta=-0.23, p=.002$, $95 \% \mathrm{Cl}=-0.37,-0.08)$, well-being and self-care $(\beta=-0.15, p=.042$, $95 \% \mathrm{Cl}=-0.29,-0.01)$, functional readaptation $(\beta=-0.16, p=.027$, $95 \% \mathrm{Cl}=-0.30,-0.02)$, responsibility and rigour $(\beta=-0.18, p=.005$, $95 \% \mathrm{Cl}=-0.31,-0.05)$ and the overall perceived QNC $(\beta=-0.19$, $p=.001,95 \% \mathrm{Cl}=-0.31,-0.08)$. Finally, a unit increase in patient/ visitor incivility scores caused $0.13(p=.010,95 \% \mathrm{Cl}=-0.23,-0.03)$ and $0.09(p=.041,95 \% \mathrm{Cl}=-0.18,-0.00)$ unit drops in the responsibility and rigour subscale score and overall QNC score, respectively (Tables 4 and 5).

\section{4 | DISCUSSION}

This descriptive and cross-sectional investigation was designed to examine the influence of WPI on the QNC scale in two hospitals in Saudi Arabia. In this study, nurses perceived their QNC to be moderate, which is lower than the findings of the previous study conducted amongst Mongolian (Gaalan, Kunaviktikul, Akkadechanunt, Wichaikhum, \& Turale, 2019), American (Lin, 2014) and Belgian (Van Bogaert, Kowalski, Weeks, Van heusden, \& Clarke, 2013) nurses but slightly higher than that of Iranian nurses (Khaki, Esmaeilpourzanjani, \& Mashouf, 2018). Nurses from different countries are likely to have 
TABLE 1 Results of the descriptive analyses of the items and subscales in the quality of nursing care scale $(n=378)$

\begin{tabular}{|c|c|c|}
\hline Item & Mean & $S D$ \\
\hline Patient satisfaction & 3.27 & 0.72 \\
\hline $\begin{array}{l}\text { I show respect for the abilities, beliefs, values and } \\
\text { desires of individual patient while providing nurs- } \\
\text { ing care }\end{array}$ & 3.45 & 0.79 \\
\hline $\begin{array}{l}\text { I am constantly seeking to show empathy in interac- } \\
\text { tions with my patient (patient's family) }\end{array}$ & 3.26 & 0.86 \\
\hline $\begin{array}{l}\text { I involved significant cohabitants of individual } \\
\text { patient in the nursing care process }\end{array}$ & 3.10 & 0.90 \\
\hline Health promotion & 3.08 & 0.74 \\
\hline $\begin{array}{l}\text { I identify the health situation of the population and } \\
\text { the resources of patient/family and community }\end{array}$ & 3.08 & 0.83 \\
\hline $\begin{array}{l}\text { I use the hospitalization time to promote healthy } \\
\text { lifestyles }\end{array}$ & 3.02 & 0.87 \\
\hline $\begin{array}{l}\text { I provide information that generates cognitive } \\
\text { learning and new abilities in the patient }\end{array}$ & 3.15 & 0.85 \\
\hline Prevention of complications & 3.17 & 0.72 \\
\hline I identify potential problems of the patient & 3.19 & 0.77 \\
\hline $\begin{array}{l}\text { I prescribe and perform interventions to prevent } \\
\text { complications }\end{array}$ & 3.15 & 0.83 \\
\hline $\begin{array}{l}\text { I evaluate the interventions that help prevent prob- } \\
\text { lems or minimize undesirable effects }\end{array}$ & 3.18 & 0.79 \\
\hline Well-being and self-care & 3.16 & 0.76 \\
\hline $\begin{array}{l}\text { I identify patient's problems that will help improve } \\
\text { the patient's well-being and daily activities }\end{array}$ & 3.20 & 0.85 \\
\hline $\begin{array}{l}\text { I prescribe and perform interventions that will help } \\
\text { improve the patient's well-being and daily activities }\end{array}$ & 3.14 & 0.88 \\
\hline $\begin{array}{l}\text { I evaluate the interventions that help improve the } \\
\text { patient's well-being and daily activities }\end{array}$ & 3.16 & 0.86 \\
\hline $\begin{array}{l}\text { I address problematic situations identified that will } \\
\text { help improve the patient's well-being and daily } \\
\text { activities }\end{array}$ & 3.13 & 0.83 \\
\hline Functional readaptation & 3.09 & 0.76 \\
\hline I ensure continuity of nursing service provision & 3.15 & 0.82 \\
\hline $\begin{array}{l}\text { I plan discharge of hospitalized patients in health } \\
\text { institutions, according to each patient's needs and } \\
\text { community resources }\end{array}$ & 3.02 & 0.89 \\
\hline $\begin{array}{l}\text { I optimize the abilities of the patient and his/her } \\
\text { significant cohabitants to manage the prescribed } \\
\text { therapy }\end{array}$ & 3.04 & 0.88 \\
\hline $\begin{array}{l}\text { I teach, instruct and train patients for their indi- } \\
\text { vidual adaptation and teach, instruct and train } \\
\text { patients on what is required for their functional } \\
\text { readaptation }\end{array}$ & 3.14 & 0.86 \\
\hline Nursing care organisation & 3.20 & 0.80 \\
\hline I know how to handle the nursing record system & 3.20 & 0.86 \\
\hline I know the hospital's policies & 3.20 & 0.84 \\
\hline Responsibility and rigour & 3.11 & 0.71 \\
\hline $\begin{array}{l}\text { I show responsibility for the decisions I make and } \\
\text { for the acts I perform and delegate, aiming to } \\
\text { prevent complications }\end{array}$ & 3.15 & 0.81 \\
\hline
\end{tabular}

(Continues)
TABLE 1 (Continued)

\begin{tabular}{|llll}
\hline Item & Mean & SD \\
\hline $\begin{array}{l}\text { I show responsibility for the decisions I make and } \\
\text { for the acts I perform and delegate, aiming to } \\
\text { ensure well-being and self-care of patients }\end{array}$ & 3.16 & 0.83 \\
\hline $\begin{array}{l}\text { I show technical/scientific rigor in the implementa- } \\
\text { tion of nursing interventions aiming to prevent } \\
\text { complications }\end{array}$ & 3.12 & 0.87 \\
$\begin{array}{l}\text { I show technical/scientific rigor in the implementa- } \\
\text { tion of nursing interventions that help improve the } \\
\text { patient's well-being and daily activities }\end{array}$ & 3.12 & 0.77 \\
$\begin{array}{l}\text { I refer problematic situations to other professionals, } \\
\text { according to the social mandates }\end{array}$ & 3.05 & 0.87 \\
$\begin{array}{l}\text { I supervise the activities that support nursing inter- } \\
\text { ventions and the activities I delegate }\end{array}$ & 3.06 & 0.85 \\
\hline \begin{tabular}{l} 
Overall perceived quality of nursing care \\
\hline
\end{tabular} & 3.14 & 0.66 \\
\hline
\end{tabular}

different views on QNC because of differences in cultural backgrounds and perceptions of the characteristics of care. This finding is worth noting because many shortcomings, such as medical errors, poor performance, lack of positive organisational climate, insufficient resources and understaffing, have been reported in hospitals in Saudi Arabia (Alenezi et al., 2019; Aljuaid, Mannan, Chaudhry, Rawaf, \& Majeed, 2016). These issues challenge nurses to improve their QNC as required in the clinical setting. Assessing the QNC delivered by nurses is critical in maintaining and improving their quality of care. Nevertheless, these data must be interpreted with caution because the previous literature uses a different QNC assessment tool, and a different QNC scale may affect the validity of the results. Thus, further research on this area is warranted.

Providing high QNC means that a patient should be satisfied with the care provided. Findings reveal that the patient satisfaction category was rated highest amongst the seven categories of the QNC scale measured in this study. Consistent with the present results, a previous study demonstrated that nurses believed that if they undertake their duties and responsibilities towards patients seriously, they will feel optimistic and satisfied that they are providing major healthcare contributions (Cruz, Cabrera, Hufana, Alquwez, \& Almazan, 2018). In terms of patient perception, several reasons may explain why Arab patients are satisfied with the QNC rendered. First, the hygiene of the environment and competence of nurses were observed (Mohamed et al., 2015). Second, some patients believe that being discharged from the hospital with appreciation and without criticism is appropriate (Skär \& Söderberg, 2018). Again, however, caution must be exercised when interpreting the results because patients are identified as experts in receiving QNC, and their perception may be different from the self-reported responses of nurses. A different respondent may have a different perception of quality of care.

Health promotion (HP) was rated as the lowest category, consistent with the previous literature on nurse perception. This finding indicates that HP is considered the least important in clinical settings (Kieft et al., 2014). According to Kumar and Preetha (2012), whilst HP 


\begin{tabular}{|c|c|c|c|c|}
\hline Variable & Mean & $S D$ & Statistical test & $p$ \\
\hline Age & & & $r=.10$ & .056 \\
\hline $\begin{array}{l}\text { Total years of experience as } \\
\text { a nurse }\end{array}$ & & & $r=.09$ & .074 \\
\hline $\begin{array}{l}\text { Total years of experience as a } \\
\text { nurse in Saudi Arabia }\end{array}$ & & & $r=.08$ & .132 \\
\hline $\begin{array}{l}\text { Total years of experience as a } \\
\text { nurse in the present hospital }\end{array}$ & & & $r=.12$ & $.016^{*}$ \\
\hline \multicolumn{5}{|l|}{ Hospital } \\
\hline Hospital A & 2.97 & 0.74 & $t=-10.60$ & $<.001^{* * *}$ \\
\hline Hospital B & 3.49 & 0.19 & & \\
\hline \multicolumn{5}{|l|}{ Gender } \\
\hline Male & 3.13 & 0.71 & $t=0.12$ & .903 \\
\hline Female & 3.15 & 0.65 & & \\
\hline \multicolumn{5}{|l|}{ Nationality } \\
\hline Saudi & 3.13 & 0.75 & $F=0.07$ & .935 \\
\hline Filipino & 3.16 & 0.64 & & \\
\hline Indian & 3.15 & 0.61 & & \\
\hline \multicolumn{5}{|l|}{ Marital status } \\
\hline Single & 3.15 & 0.66 & $t=0.06$ & .951 \\
\hline Married & 3.14 & 0.66 & & \\
\hline \multicolumn{5}{|l|}{ Educational level } \\
\hline Diploma in nursing & 3.22 & 0.62 & $t=1.21$ & .226 \\
\hline Baccalaureate in nursing & 3.12 & 0.67 & & \\
\hline \multicolumn{5}{|l|}{ Working area } \\
\hline Emergency Room & 3.06 & 0.76 & $F=1.31$ & .235 \\
\hline Outpatient Department & 3.39 & 0.45 & & \\
\hline Medical Department & 3.07 & 0.73 & & \\
\hline Surgical Department & 3.07 & 0.67 & & \\
\hline Intensive Care Units & 3.08 & 0.68 & & \\
\hline Operating Room & 3.25 & 0.54 & & \\
\hline Obstetric Department & 3.23 & 0.70 & & \\
\hline Artificial Kidney Unit & 3.37 & 0.55 & & \\
\hline Paediatric Department & 3.22 & 0.50 & & \\
\hline
\end{tabular}

TABLE 2 Results of the inferential statistics examining the associations and differences between the overall perceptions of quality of nursing care and the demographic and work-related variables $(n=378)$

${ }^{*}$ Significant at 0.05 .

*** Significant at 0.001 .

is an important element in public health practice, prompt treatment is a priority in hospital practice amongst nurses. Kemppainen et al. (2012) stated that HP provides the understanding and information required to allow patients to recognise their own responsibility. In other words, HP places emphasis on the prevention of disease and health education. In the analysis of Lavin, Harper, and Barr (2015), nurses consider managing and assessing treatment high priority, especially if the patient is in critical condition (e.g., comatose, postsurgery and haemorrhagic). If the patient stabilises, they then provide invaluable physical and emotional support. Indeed, most nurses work in physically challenging situations (Cruz, 2017), thus implying that disease treatment has higher priority than HP. Nevertheless, HP should also be imparted during patient hospitalisation for their recovery.
Another important finding of this work is that the greater the length of experience in the present hospital, the better the QNC. That is, the longer the working experience, the higher the quality of healthcare service delivered. This finding is consistent with early observations that indicated that Korean nurses with longer hospital experience perform better than new graduate nurses (Ryu \& Kim, 2018), likely because new nurses lack knowledge of the management process and adequate clinical experience. Nurses with experience are more acquainted with the hospital management process. Overall, constant self-improvement is needed in nursing to improve the nursing services delivered.

The current study found that Hospital B nurses perceived their QNC to be higher and better than that of Hospital A nurses. A 
TABLE 3 Results of the multivariate regression analysis examining the multivariate effects of the predictor variables on the dimensions of quality of nursing care with Wilks' lambda test $(n=378)$

\begin{tabular}{|c|c|c|c|c|c|}
\hline Effect & Value & $F$ & Hypothesis df & Error $d f$ & $p$ \\
\hline Hospital & 0.69 & 19.67 & 8.000 & 355.00 & $<.001^{* * *}$ \\
\hline Age & 0.96 & 1.72 & 8.00 & 355.00 & .093 \\
\hline Gender & 0.98 & 0.89 & 8.00 & 355.00 & .522 \\
\hline Nationality & 0.97 & 1.34 & 8.00 & 355.00 & .221 \\
\hline Marital status & 0.99 & 0.41 & 8.00 & 355.00 & .914 \\
\hline Education & 0.98 & 1.00 & 8.00 & 355.00 & .436 \\
\hline $\begin{array}{l}\text { Total years of experi- } \\
\text { ence as a nurse }\end{array}$ & 0.99 & 0.60 & 8.00 & 355.00 & .780 \\
\hline $\begin{array}{l}\text { Total years of experi- } \\
\text { ence as a nurse in Saudi } \\
\text { Arabia }\end{array}$ & 0.98 & 1.12 & 8.00 & 355.00 & .348 \\
\hline $\begin{array}{l}\text { Total years of experi- } \\
\text { ence as a nurse in the } \\
\text { present hospital }\end{array}$ & 0.96 & 1.90 & 8.00 & 355.00 & .059 \\
\hline Working area & 0.98 & 0.79 & 8.00 & 355.00 & .614 \\
\hline General Incivility & 0.95 & 2.15 & 8.00 & 355.00 & $.031^{*}$ \\
\hline Nurse Incivility & 0.96 & 2.10 & 8.00 & 355.00 & $.035^{*}$ \\
\hline Supervisor Incivility & 0.98 & 0.99 & 8.00 & 355.00 & .441 \\
\hline Physician Incivility & 0.96 & 1.73 & 8.00 & 355.00 & .091 \\
\hline $\begin{array}{l}\text { Patient/Visitor } \\
\text { Incivility }\end{array}$ & 0.97 & 1.51 & 8.00 & 355.00 & .153 \\
\hline
\end{tabular}

*Significant at 0.05 .

***Significant at 0.001 level. probable explanation for this finding is that Hospital $B$ has a smaller bed capacity (300 beds) than Hospital A (450 beds). Delamater, Messina, Grady, WinklerPrins, and Shortridge (2013) elaborated that a higher bed capacity means a greater number of patients to care for, which may affect QNC and job performance. Higher bed capacities and patient numbers could increase a nurse's workload and eventually lead to burnout and job dissatisfaction (Delamater et al., 2013). Comparably, Lake et al. (2016) reported that ICU nurses with 20 or more beds experience burnout more often than those in smaller ICUs with less than 10 beds. In a literature review, Glette, Aase, and Wiig (2017) found that a greater bed capacity means a higher workload for nurses, especially for an understaffed hospital, and a possible compromise in a nurse's ability to provide safe care. These data must be interpreted with caution because the staffing pattern was not measured in the present study. Given this information gap, the effects of staffing patterns on QNC must be assessed in a future study.

Hospital, general incivility and nurse incivility influence QNC. The present study makes several noteworthy findings pertaining to overall incivility that nurses experience in clinical settings. These results are consistent with findings in various countries, such as Iran (Abdollahzadeh et al., 2017), Palestine (Jaradat et al., 2016) and the USA (Oyeleye et al., 2013), where nurses reportedly experience frequent incivility from the workplace, the co-workers, supervisors and other HCWs. Hospital incivility is related to job design, such as role conflict, minimal autonomy, high uncertainty and lack of cooperation, all of which may result in poor job outcomes (Jaradat et al.,
2016). Incivility frequently begins when nurses experience increased competition amongst co-workers, low social support and autocratic and task-oriented leadership style (Kaiser, 2016). As such, given that nursing administration has the power to govern the work environment and relationships of employees, all efforts should be directed towards maintaining quality administration to prevent incivility problems from occurring.

An important highlight of this study is the finding of the negative impact of general incivility amongst nurses on QNC, which means the greater the general incivility experienced by nurses, the poorer their QNC rendered. Internationally, the results obtained are consistent with a number of studies, and reports have increased the apprehension concerning the effect of incivility on the overall work performance of nurses (Abdollahzadeh et al., 2017; Jaradat et al., 2016; Oyeleye et al., 2013). For example, incivility experience can change a nurse's thought process and behaviour (Abdollahzadeh et al., 2017), decrease collaboration, increase nonattendance, result in poor work performance and cause medication errors (Jaradat et al., 2016; Shi et al., 2018; Spiri et al., 2016; Zhou et al., 2015), all of which clearly affect a nurse's patient quality care performance.

The results further showed that nurses' incivility negatively affects the prevention of complications, well-being and self-care, responsibility and rigour and overall QNC. This result seems to be consistent with those of other studies that reported the dangerous effects of incivility behaviours on the overall well-being and quality care of patients (Zhou et al., 2015). Specifically, at the individual level, a previous study demonstrated that individuals' QNC in the workplace is mainly 


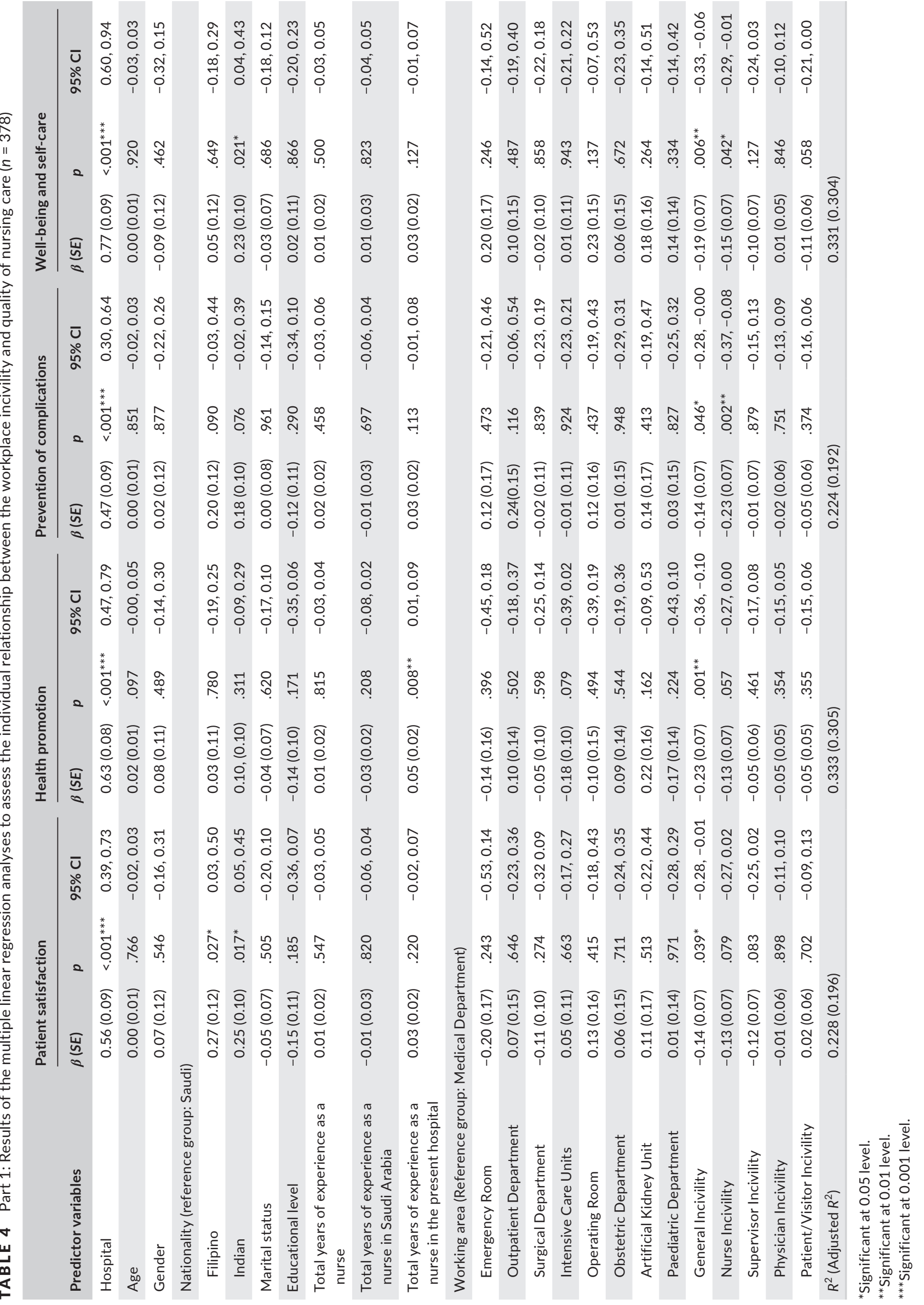




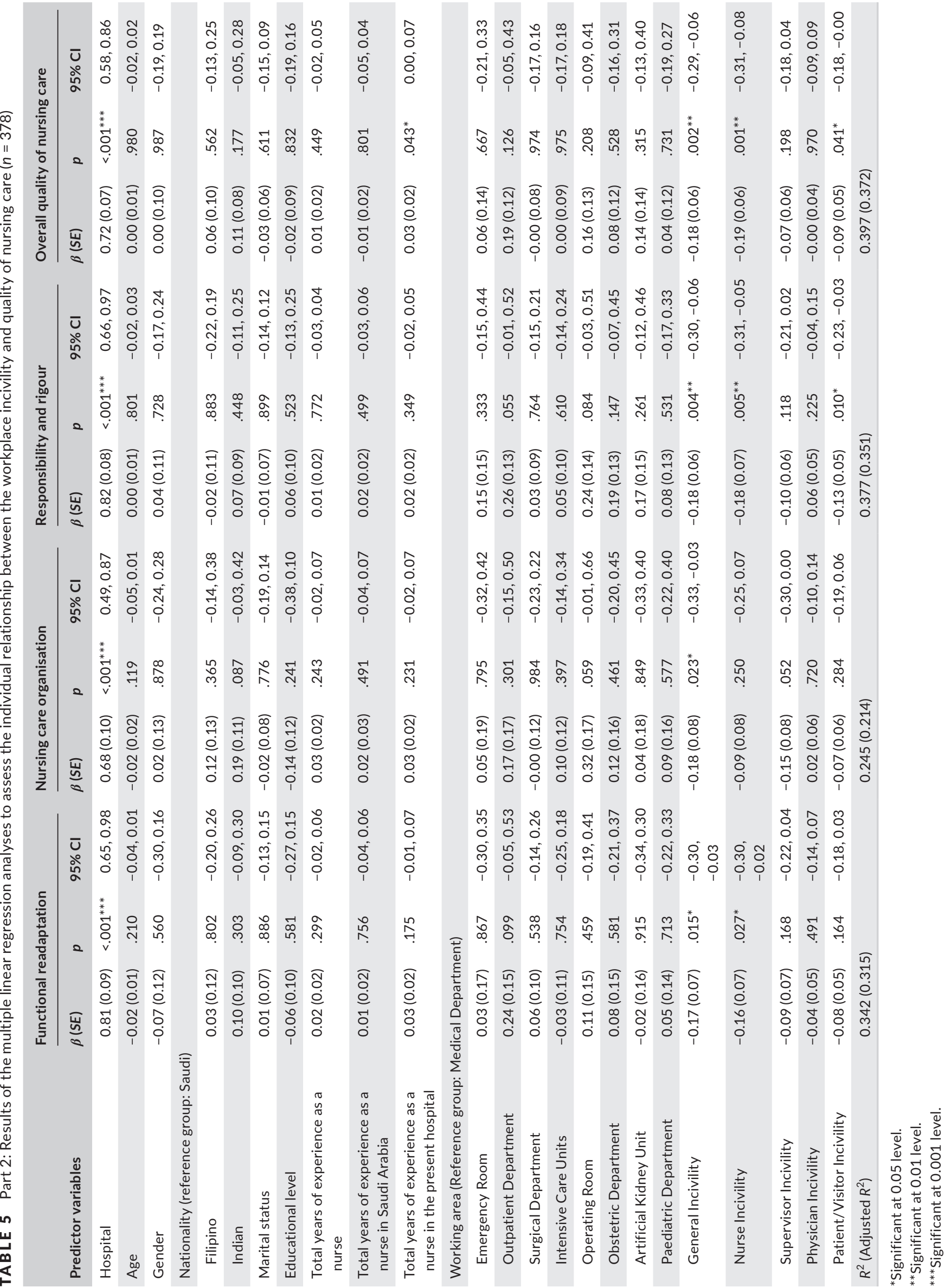


regulated by their attitudes and consequent behaviours. Nurses are easy targets of WPI from their managers and co-workers (Zhou et al., 2015). Those who experience harmful incidents have a higher chance of developing poor well-being and self-care, which might weaken their work performance, than those who do not. In the analysis of Zhang et al. (2018), incivility unfavourably sets back the cognitions and emotions of nurses and significantly reduces their self-confidence towards patient care. Poor self-confidence towards care and responsibility could lead to low QNC. A harmonious compassionate milieu can increase in providing humanistic (Zhang et al., 2018).

Finally, nurses' experience of patient/visitor incivility has a negative impact on the dimension responsibility and rigour and overall QNC. These results corroborate previous findings that $6 \%-85 \%$ of nurses experience patient/visitor incivility, probably because of the status of the nursing profession in Saudi Arabia (Kennedy \& Julie, 2013; Shi et al., 2018). Saudi Arabia has relied exclusively on recruiting expatriate registered nurses, who constitute $63.82 \%$ of the total HCP population (Alsulaimani, 2014). In addition, many patients avail of services for free, resulting in congestion and increased nurses' workload and job stress (Alkorashy \& Al Moalad, 2016). Similarly, the cultural diversity between nurses and patients could affect the performance of the former in patient care. In a study by AlYami and Watson (2014), expatriate nurses were frequently unacquainted with Saudi's healthcare system, which may impact their patient care performance and increase the risk of interpersonal conflict with patients and visitors. Alternatively, expatriate nurses may struggle to learn the Arabic language (Aldossary, 2013). Miscommunication is often mentioned as a cause of incivility because most expatriate nurses do not speak Arabic, and some patients and their carers lack English skills; this gap could generate a barrier in communication (Aldossary, 2013). Additionally, communication amongst the nursing staff is seldom successful because the nurses may belong to different cultural backgrounds and have different standards and attitudes. In-depth and respectful communication with the patients and their families through a medical translator must be introduced during the early treatment stage (Abolfazl Vagharseyyedin, 2015).

\section{1 | Limitations of the study}

The study has some limitations that may affect its outcomes and should be acknowledged. First, the results were based on a sample of two public hospitals, which could limit the generalisability of the results. A larger nursing population from other hospitals, including private hospitals, should be included to enable the wider generalisation of the findings. Second, a self-reported questionnaire was used in the study; thus, the results may include respondent bias. Respondents may have underreported or indicated favourable answers to avoid criticism. Third, is that cross-sectional data limit causal inference? Despite these limitations, however, a major strength of this study is that a standardised instrument with good psychometric properties was used. A high response rate was also found. The findings illustrate the importance of issues affecting WPI on QNC in two hospitals in Saudi Arabia.

\section{5 | CONCLUSIONS}

The current study assessed the influence of WPI on QNC in two hospitals in Saudi Arabia. Nurses perceived a moderate level of QCN, and, amongst the different dimensions of QNC, health promotion was perceived to have the lowest quality. Nurses with more hospital experiences perceived better QNC rendered than those with less hospital experiences. Hospital type, general incivility and nurse incivility were associated with QNC dimensions (e.g., patient satisfaction, health promotion, prevention of complication, well-being and self-care, functional readaptation, nursing care organisation and responsibility and rigour). Furthermore, nurse incivility experience negatively affected their job tasks, such as prevention of complications, well-being and self-care and responsibility and rigour, as well as their overall QNC. Finally, nurses' experience of patient/visitor incivility had a negative influence on the responsibility and rigour dimension and in overall QCN. Hence, the findings of this survey provide valuable inputs in improving QNC by intervening in incivility issues from different sources in the hospital.

\section{6 | RELEVANCE TO CLINICAL PRACTICE}

The study findings identify the negative impact of nurses' experiences of incivility from different sources on the QNC provided to patients. Hence, this study supports the call to stop incivility in hospitals. To overcome incivility and improve QNC, nursing management should constantly implement quality management approaches; for example, (a) well-experienced nurses can arrange and supervise newly hired nurses, (b) the nurse-to-patient ratio can be improved based on bed capacity and (c) health promotion can be undertaken based on comprehensive knowledge and patient education to increase the QNC delivered. The management is also knowledgeable about ways to reduce incivility. Thus, nurses must be trained regarding incivility, its factors, how to recognise uncivil acts, how to approach uncivil acts and ways to prevent it. Having a nurturing workplace environment where individuals respect one another and have effective communication skills, such as sensitivity to differences, is recommended. Communication skills training should be given during orientations for newly hired nurses and everyday practice. Finally, nursing administration should give time and constantly support nurses in implementing HP roles whilst performing patient care. Likewise, given that patients offer essential information regarding QNC, including them in healthcare planning can be of help in maintaining QNC.

\section{ACKNOWLEDGEMENTS}

The authors are thankful to the Deanship of Scientific Research through the Research Center at the College of Nursing, King Saud University for the support of this research project. 


\section{CONFLICT OF INTEREST}

No conflict of interest.

\section{AUTHORS' CONTRIBUTIONS}

Drafting the manuscript or revising it critically: ASA, NA, JA, JPC. All authors made substantial contributions to conception and design, acquisition of data, or analysis and interpretation of data; given final approval of the version to be published; and agreed to be accountable for all aspects of the work in ensuring that questions related to the accuracy or integrity of any part of the work are appropriately investigated and resolved. Each author should have participated sufficiently in the work to take public responsibility for appropriate portions of the content.

\section{ORCID}

Abdualrahman Saeed Alshehry (iD https://orcid. org/0000-0001-8354-7762

Joseph Almazan (iD https://orcid.org/0000-0001-5148-6889 Jonas Preposi Cruz (iD https://orcid.org/0000-0002-3758-1414

\section{REFERENCES}

Abdollahzadeh, F., Asghari, E., Ebrahimi, H., Rahmani, A., \& Vahidi, M. (2017). How to prevent workplace incivility?: Nurses' perspective. Iranian Journal of Nursing and Midwifery Research, 22(2), 157-163. https://doi.org/10.4103/1735-9066.205966

Abolfazl Vagharseyyedin, S. (2015). Workplace incivility: A concept analysis. Contemporary Nurse, 50(1), 115-125. https://doi. org/10.1080/10376178.2015.1010262

Aldossary, A. (2013). The role legitimacy of nurses in Saudi Arabia. Journal of HealthSpecialties, 1(1),28.https://doi.org/10.4103/1658-600X.110671

Alenezi, A., Pandaan, R. P. M., Almazan, J. U., Pandaan, I. N., Casison, F. S., \& Cruz, J. P. (2019). Clinical practitioners' perception of the dimensions of patient safety culture in a government hospital: A onesample correlational survey. Journal of Clinical Nursing. https://doi. org/10.1111/jocn.15038

Al-Hussami, M., Al-Momani, M., Hammad, S., Maharmeh, M., \& Darawad, M. (2017). Patients' perception of the quality of nursing care and related hospital services. Health and Primary Care, 1(2), 1-6. https://doi. org/10.15761/HPC.1000110

Aljuaid, M., Mannan, F., Chaudhry, Z., Rawaf, S., \& Majeed, A. (2016). Quality of care in university hospitals in Saudi Arabia: A systematic review. British Medical Journal Open, 6(2), e008988. https://doi. org/10.1136/bmjopen-2015-008988

Alkorashy, H., \& Al Moalad, F. (2016). Workplace violence against nursing staff in a Saudi university hospital. International Nursing Review, 63(2), 226-232. https://doi.org/10.1111/inr.12242

Almutairi, K. M. (2015). Culture and language differences as a barrier to provision of quality care by the health workforce in Saudi Arabia. Saudi Medical Journal, 36(4), 425-431. https://doi.org/10.15537/ smj.2015.4.10133

Alshehry, A. S., Alquwez, N., Almazan, J. U., Namis, I. M., Moreno-Lacalle, R. C., \& Cruz, J. P. (2019). Workplace incivility and its influence on professional quality of life amongst nurses from multicultural background: A cross-sectional study. Journal of Clinical Nursing, 28(13-14), 2553-2564.
Alsulaimani, A. (2014). Practical competency of Filipino nurses working in Taif city, Kingdom of Saudi Arabia. Saudi Journal for Health Sciences, 3, 85-91. https://doi.org/10.4103/2278-0521.134859

AlYami, M., \& Watson, R. (2014). An overview of nursing in Saudi Arabia. Journal of Health Specialties, 2(1), 10. https://doi. org/10.4103/1658-600X.126058

American Nurses Association [ANA] (2019). Violence, incivility, \& bullying. Retrieved 19 February 2019, from https://www.nursingworld.org/ practice-policy/work-environment/violence-incivility-bullying

Cohen, J. (1977). Statistical power analysis for the behavioral sciences. New York, NY: Routledge.

Cruz, J. P. (2017). Quality of life and its influence on clinical competence among nurses: A self-reported study. Journal of Clinical Nursing, 26(34), 388-399. https://doi.org/10.1111/jocn.13402

Cruz, J. P., Cabrera, D. N. C., Hufana, O. D., Alquwez, N., \& Almazan, J. (2018). Optimism, proactive coping and quality of life among nurses: A cross-sectional study. Journal of Clinical Nursing, 27(9-10), 20982108. https://doi.org/10.1111/jocn.14363

Delamater, P., Messina, J., Grady, S., WinklerPrins, V., \& Shortridge, A. (2013). Do more hospital beds lead to higher hospitalization rates? A spatial examination of Roemer's Law. PLoS ONE, 8(2), e54900. https ://doi.org/10.1371/journal.pone.0054900

Faul, F., Erdfelder, E., Buchner, A., \& Lang, A.-G. (2009). Statistical power analyses using $G^{*}$ Power 3.1: Tests for correlation and regression analyses. Behavior Research Methods, 41, 1149-1160. https://doi. org/10.3758/BRM.41.4.1149

Freitas, J. S., Silva, A. E., Minamisava, R., Bezerra, A. L., \& Sousa, M. R. (2014). Quality of nursing care and satisfaction of patients attended at a teaching hospital. Revista latino-americana de Enfermagem, 22(3), 454-460. https://doi.org/10.1590/0104-1169.3241.2437

Gaalan, K., Kunaviktikul, W., Akkadechanunt, T., Wichaikhum, O., \& Turale, S. (2019). Factors predicting quality of nursing care among nurses in tertiary care hospitals in Mongolia. International Nursing Review, 66(2), 176-182. https://doi.org/10.1111/inr.12502

Glette, M., Aase, K., \& Wiig, S. (2017). The relationship between understaffing of nurses and patient safety in hospitals-A literature review with thematic analysis. Open Journal of Nursing, 7(12), 1387-1429. https://doi.org/10.4236/ojn.2017.712100

Guidroz, A. M., Burnfield-Geimer, J. L., Clark, O., Schwetschenau, H. M., \& Jex, S. M. (2010). The nursing incivility scale: Development and validation of an occupation-specific measure. Journal of Nursing Measurement, 18(3), 176. https://doi.org/10.1891/1061-3749.18.3.176

Heydari, A., Rad, M., \& Rad, M. (2015). Evaluating the incivility between staff nurses and matrons employed in Iran. Acta Facultatis Medicae Naissensis, 32(2), 137-146.

Holm, K., Torkelson, E., \& Backstrom, M. (2015). Models of workplace incivility: The relationships to instigated incivility and negative outcomes. BioMed Research International, 2015, 1-10. https://doi. org/10.1155/2015/920239

Ibrahim, S. A. E. A., \& Qalawa, S. A. (2016). Factors affecting nursing students' incivility: As perceived by students and faculty staff. Nurse Education Today, 36, 118-123. https://doi.org/10.1016/j.nedt.2015.08.014

Jaradat, Y., Nielsen, M. B., Kristensen, P., Nijem, K., Bjertness, E., Stigum, H., \& Bast-Pettersen, R. (2016). Workplace aggression, psychological distress, and job satisfaction among Palestinian nurses: A crosssectional study. Applied Nursing Research, 32, 190-198. https://doi. org/10.1016/j.apnr.2016.07.014

Joint Commission [JC] (2008). Behaviors that undermine a culture of safety. Retrieved from http://www.jointcommissionorg/SentinelEvents/ SentinelEventAlert/sea_40.htm

Kaiser, J. (2016). The relationship between leadership style and nurseto-nurse incivility: Turning the lens inward. Journal of Nursing Management, 25(2), 110-118. https://doi.org/10.1111/jonm.12447

Kemppainen, V., Tossavainen, K., \& Turunen, H. (2012). Nurses' roles in health promotion practice: An integrative review. Health Promotion 
International, 28(4), 490-501. https://doi.org/10.1093/heapro/ das034

Kennedy, M., \& Julie, H. (2013). Nurses' experiences and understanding of workplace violence in a trauma and emergency department in South Africa. Health SA Gesondheid, 18(1), 1-9. https://doi. org/10.4102/hsag.v18i1.663

Khaki, S., Esmaeilpourzanjani, S., \& Mashouf, S. (2018). Nursing cares quality in nurses. Scientific Journal of Nursing, Midwifery and Paramedical Faculty, 3(4), 1-14. https://doi.org/10.29252/sjnmp.3.4.1

Kieft, R., de Brouwer, B., Francke, A., \& Delnoij, D. (2014). How nurses and their work environment affect patient experiences of the quality of care: A qualitative study. BMC Health Services Research, 14(1), 1-10. https://doi.org/10.1186/1472-6963-14-249

Kumar, S., \& Preetha, G. (2012). Health promotion: An effective tool for global health. Indian Journal of Community Medicine, 37(1), 5. https:// doi.org/10.4103/0970-0218.94009

Lake, E. T., Hallowell, S. G., Kutney-Lee, A., Hatfield, L. A., Del Guidice, M., Boxer, B. A., Ellis, L. N., Verica, L., ... Aiken, L. H. (2016). Higher quality of care and patient safety associated with better NICU work environments. Journal of Nursing Care Quality, 31(1), 24-32. https:// doi.org/10.1097/NCQ.0000000000000146

Lavin, M. A., Harper, E., \& Barr, N. (2015). Health information technology, patient safety, and professional nursing care documentation in acute care settings. Online Journal of Issues in Nursing, 20(2), 6.

Lin, H. (2014). Revisiting the relationship between nurse staffing and quality of care in nursing homes: An instrumental variables approach. Journal of Health Economics, 37, 13-24. https://doi.org/10.1016/j. jhealeco.2014.04.007

Loi, N. M., Loh, J. M., \& Hine, D. W. (2015). Don't rock the boat: The moderating role of gender in the relationship between workplace incivility and work withdrawal. Journal of Management Development, 34(2), 169-186. https://doi.org/10.1108/JMD-12-2012-0152

Martins, M. M. F. P. D., Gonçalves, M. N. D. C., Ribeiro, O. M. P. L., \& Tronchin, D. M. R. (2016). Quality of nursing care: Instrument development and validation. Revista Brasileira de Enfermagem, 69(5), 920-926.

Mohamed, E. Y., Sami, W., Alotaibi, A., Alfarag, A., Almutairi, A., \& Alanzi, F. (2015). Patients' satisfaction with primary health care centers' services, Majmaah, Kingdom of Saudi of Saudi Arabia. International Journal of Health Sciences, 9(2), 163-170. https://doi.org/10.12816/ 0024113

Oyeleye, O., Hanson, P., O'Connor, N., \& Dunn, D. (2013). Relationship of workplace incivility, stress, and burnout on nurses' turnover intentions and psychological empowerment. Journal of Nursing Administration, 43(10), 536-542. https://doi.org/10.1097/NNA.0b013e3182a3e8c9

Pearson, C. M., Andersson, L. M., \& Wegner, M. J. (2001). When workers flout convention: A study of workplace incivility. Human Relations, 11, 1387-1419. https://doi.org/10.1177/00187267015411001
Ryu, J., \& Kim, K. (2018). The influence of nursing care integration services on nurses' work satisfaction and quality of nursing care. Journal of Nursing Management, 26(8), 1024-1032. https://doi.org/10.1111/ jonm.12629

Shi, Y., Guo, H., Zhang, S., Xie, F., Wang, J., Sun, Z., Dong, X., Sun, T., ... Fan, L. (2018). Impact of workplace incivility against new nurses on job burn-out: A cross-sectional study in China. British Medical Journal Open, 8(4), e020461. https://doi.org/10.1136/bmjop en-2017-020461

Skär, L., \& Söderberg, S. (2018). Patients' complaints regarding healthcare encounters and communication. Nursing Open, 5(2), 224-232. https://doi.org/10.1002/nop2.132

Spiri, C., Brantley, M., \& McGuire, J. (2016). Incivility in the workplace: A study of nursing staff in the Military Health System. Journal of Nursing Education and Practice, 7(3), 40. https://doi.org/10.5430/ jnep.v7n3p40

Van Bogaert, P., Kowalski, C., Weeks, S. M., Van heusden, D., \& Clarke, S. P. (2013). The relationship between nurse practice environment, nurse work characteristics, burnout and job outcome and quality of nursing care: A cross-sectional survey. International Journal of Nursing Studies, 50(12), 1667-1677. https://doi.org/10.1016/j.ijnur stu.2013.05.010

Zhang, S., Ma, C., Meng, D., Shi, Y. U., Xie, F., Wang, J., ... Sun, T. (2018). Impact of workplace incivility in hospitals on the work ability, career expectations and job performance of Chinese nurses: A cross-sectional survey. British Medical Journal Open, 8(12), e021874. https:// doi.org/10.1136/bmjopen-2018-021874

Zhou, Z. E., Yan, Y., Che, X. X., \& Meier, L. L. (2015). Effect of workplace incivility on end-of-work negative affect: Examining individual and organizational moderators in a daily diary study. Journal of Occupational Health Psychology, 20(1), 117. https://doi.org/10.1037/ a0038167

\section{SUPPORTING INFORMATION}

Additional supporting information may be found online in the Supporting Information section at the end of the article.

How to cite this article: Alshehry AS, Alquwez N, Almazan J, Namis IM, Cruz JP. Influence of workplace incivility on the quality of nursing care. J Clin Nurs. 2019;28:4582-4594. https ://doi.org/10.1111/jocn.15051 